\title{
EchoGéo
}

$34 \mid 2015$

Varia

\section{Mobilités ici et ailleurs}

Jean-Louis Chaléard

\section{(2) OpenEdition}

Journals

\section{Édition électronique}

URL : https://journals.openedition.org/echogeo/14431

DOI : 10.4000/echogeo.14431

ISSN : 1963-1197

\section{Éditeur}

Pôle de recherche pour l'organisation et la diffusion de l'information géographique (CNRS UMR 8586)

Référence électronique

Jean-Louis Chaléard, « Mobilités ici et ailleurs », EchoGéo [En ligne], 34 | 2015, mis en ligne le 15 décembre 2015, consulté le 01 août 2021. URL : http://journals.openedition.org/echogeo/14431 DOI : https://doi.org/10.4000/echogeo.14431

Ce document a été généré automatiquement le 1 août 2021

EchoGéo est mis à disposition selon les termes de la licence Creative Commons Attribution - Pas d'Utilisation Commerciale - Pas de Modification 4.0 International (CC BY-NC-ND) 


\title{
Mobilités ici et ailleurs
}

\author{
Jean-Louis Chaléard
}

1 Matthieu Giroud, maître de conférences en géographie à l'Université Paris-Est Marnela-Vallée, était un des contributeurs du dernier numéro d'ÉchoGéo. Il était co-auteur du texte « Commerce de détail et changement urbain ». Il avait participé aussi à l'entretien «Lire et traduire Harvey. La pensée géographique par la brèche » du numéro 22 d'octobre-décembre 2012. Matthieu Giroud fait partie des victimes des attentats du 13 novembre 2015 au Bataclan. Nos pensées vont bien sûr d'abord à sa famille. Nous pleurons et regrettons aussi un jeune collègue, ami et collaborateur de plusieurs membres de notre équipe. Au-delà, c'est toute notre communauté de géographes qui est en deuil. Il est difficile pour une revue scientifique de réagir dans l'urgence face à l'actualité. Au demeurant, ce n'est pas son rôle. Il est aussi difficile de réagir à chaud pour des collègues frappés de douleur et de stupeur devant cette disparition. Mais Matthieu Giroud menait ou participait à de nombreuses recherches qui sont en cours. Il travaillait notamment sur les mobilités spatiales, la critique des modes de développement urbain, la gentrification et les évictions populaires, thèmes que l'on retrouve dans différentes livraisons d'Échogéo, y compris dans la présente. Achever les travaux entamés, publier ses résultats, poursuivre son œuvre constituent les meilleures réponses à apporter à la folie meurtrière qui l'a fait disparaître.

2 En 2015, comme régulièrement depuis 2011, le dernier numéro d'ÉchoGeo de l'année est un varia. On n'y trouvera donc pas un thème central autour duquel tout s'organise. Toutefois, quatre textes sur cinq de la rubrique Sur le champ abordent de façon directe ou indirecte les mobilités, que ce soit des mobilités locales, urbaines et périurbaines, internationales ou liées au tourisme. Cet intérêt est significatif de l'ampleur du phénomène et de ses conséquences dans le monde actuel marqué par l'amélioration des moyens de transports, la réduction des distances-temps, la diversité des déplacements et de leurs motifs. Plusieurs textes mènent aussi une réflexion sur la construction du territoire, sous différentes formes, en relation le plus souvent avec les mobilités: ancrage territorial d'habitants dans le périurbain francilien, construction de territoires transfrontaliers en Afrique de l'Ouest, tentatives d'aménagement de périphéries 
urbaines en croissance en Algérie, instrumentalisation du tourisme et des lieux de mémoire pour mettre en place une identité nationale en Afrique du Sud...

3 Pour autant, ce sont des thèmes fort variés qui sont abordés. Le texte de Martine Berger, Mireille Bouleau et Catherine Mangeney étudie l'évolution récente des mobilités franciliennes, caractérisées par une stabilisation des distances moyennes domicile-travail, une plus grande recherche de proximité dans les comportements et l'utilisation des ressources, des continuités entre franges de l'agglomération et périurbain proche, par rapport au centre de l'agglomération parisienne. Mohamadou Mountaga Diallo montre comment les mobilités de part et d'autre de la frontière sénégambienne contribuent à la production de territoires qui s'appuient sur de multiples réseaux, en dépit de l'existence d'États différents. Fabrice Folio propose une réflexion sur le "Dark tourisme ", visite d'endroits liés à des épisodes dramatiques, à la souffrance, à la mort, plus étudié chez les auteurs anglophones qu'en France, mais qui prend de l'ampleur. À partir du cas de l'Afrique du Sud, où sont mis en valeur les hauts lieux de l'apartheid, l'auteur montre la diversité des ressorts qui président à son développement. Youcef Kadri et Mohamed Madani analysent l'échec des différentes politiques d'aménagement urbains dans le cas d'Oran, les instruments de planification se révélant incapables d'assurer le contrôle de la croissance urbaine. Le cinquième texte est radicalement différent : Didier Soto, Florent Renard et Emmanuel ThimonierRouzet entament une réflexion sur la préfiguration d'un observatoire lyonnais du climat. Ils soulignent la nécessité de créer un réseau d'observation au regard des besoins d'acteurs multiples. Alors que se tient à Paris, en décembre 2015, la COP21, cet article rejoint donc une question d'actualité et une des inquiétudes de notre temps sur l'avenir de la planète.

Dans la rubrique Sur l'image, le texte de Nasser Rebaï s'inscrit dans les thèmes finalement dominants de ce numéro : les mobilités et les territoires. Il analyse en image les conséquences de l'émigration paysanne (principalement aux États-Unis) dans un village de la périphérie de Cuenca (sud de l'Équateur). Les illustrations servent de point de départ et de point d'appui à l'étude qui repose également sur des enquêtes de terrain, montrant comment les deux peuvent se compléter et s'enrichir mutuellement.

Serge Weber nous offre, dans la rubrique Sur l'écrit, une interview de Jean-Marc Victor à propos des nouvelles d'Eudora Welty, qui est l'occasion d'évoquer les écrivains du Sud des États-Unis, la façon dont l'auteure (et aussi photographe) américaine aborde l'espace et ce Sud, entre un certain réalisme et le jeu de la fiction qui pervertit les stéréotypes, pour conclure sur "l'invention» du Sud, mêlant ainsi étroitement réflexions sur la littérature et la géographie.

6 La rubrique Sur le métier laisse la parole à Agnès Deboulet et Khedidja Mamou qui présentent Appuii (Alternative pour des projets urbains ici et à l'international). L'association revendique une posture d'accompagnement des habitants sur la production de l'espace urbain et interroge les savoirs professionnels dans leur définition étroite. L'exposé d'un projet de cartographie urbaine collaborative en cours, qui doit, entre autres, rendre visibles des formes de participation alternatives, met en évidence l'utilisation possible de l'outil cartographique au service d'initiatives citoyennes militantes. On se rappelle ici bien sûr le célèbre essai d'Yves Lacoste « La géographie, ça sert d'abord à faire la guerre ». Le texte d'A. Reboulet et K. Mamou met en évidence la diversité des combats dans lesquels la géographie peut être engagée aujourd'hui. 